\title{
Desenvolvimento de um sistema domótico para prevenção de acidentes infantis utilizando a Plataforma Arduino
}

\author{
Leonardo Correia Resende \\ Docente - Instituto Federal de Educação, Ciência e Tecnologia do Rio de Janeiro \\ (leonardo.resende@ifrj.edu.br) \\ Aline Evangelista Silva Resende \\ Universidade do Grande Rio \\ (aline.esr@uol.com.br)
}

\begin{abstract}
Resumo: O avanço da informática, o surgimento de novas ferramentas e a globalização do mundo moderno levaram ao desenvolvimento de vários dispositivos de conforto e segurança residencial. A partir de 2005, o Arduino surgiu como uma ferramenta muito eficiente, barata e de fácil manuseio no campo da automação. Com isso, objetiva-se montar um sistema de segurança que tem como função avisar quando uma criança está na cozinha de uma residência sem a presença de um adulto. Dois sensores posicionados estrategicamente enviam um sinal para o Arduino, que aciona um sistema de alarme para identificar a presença de criança. Os sistemas devem apresentar eficiência, com segurança e comodidade para o usuário. A técnica de árvore de falhas é apresentada para identificar possíveis problemas de funcionamento. Análises de custos são realizadas para mostrar que, além de trazer comodidade e segurança, o sistema apresenta baixo custo de aquisição e manutenção e facilidade de operação por não especialistas em automação e eletrônica.
\end{abstract}

Palavras-chave: Domótica; Arduino; Automação.

\section{Development of a domotic system for prevention of children's accidents using the Arduino Platform}

\begin{abstract}
The advancement of computing, emergence of new tools and globalization of the modern world led to the development of various comfort and residential security devices. Since 2005, Arduino has emerged as a very efficient, inexpensive and easy-to-use tool in the field of automation. This aims to set up a security system that has the function of advising when a child is in the kitchen of a residence without the presence of an adult. Two strategically positioned sensors sent a signal to the Arduino that will trigger an alarm system to identify the presence of a child. The systems must present efficiency with safety and comfort for the user. The fault tree technique is presented to identify possible operating problems. Cost analyzes are carried out to show that in addition to bringing comfort and safety, the system presents low acquisition and maintenance costs and ease of operation by nonspecialists in automation and electronics.
\end{abstract}

Keywords: Domotic; Arduino; Automation.

\section{INTRODUÇÃO}

Com o desenvolvimento tecnológico atual abrangendo várias esferas, desde materiais de construção até redes de comunicação, iniciou-se o processo de 
mudança e quebra de paradigmas direcionados à habitação. Acompanhando essa mudança, surgiu a automação residencial que, por meio de sistemas de automação, permite modificar uma simples habitação em uma casa inteligente (MONTEIRO, 2015).

A automação residencial consiste de sistemas tecnológicos cuja função é oferecer diversos serviços para a residência, como segurança, comunicação, gestão de energia, bem-estar, dentre outros. O objetivo central da domótica consiste na integralização entre iluminação, entretenimento, segurança, telecomunicações, aquecimento ou ar condicionado, tudo isso controlado a partir de um sistema inteligente programável e centralizado (STOPPA, 2013).

Segundo De Andrade (2016), a automação residencial ou domótica tem aumentado a sua divulgação graças aos benefícios que são oferecidos. Ela facilita tarefas diárias, tais como controlar a rega do jardim, ligar a iluminação externa ao anoitecer, estabelecer níveis de temperatura e iluminação adequados ao usuário e a utilização de sensores de presença que são colocadas para desligar as luzes quando o cômodo da casa está vazio. Dessa forma, a domótica tem por objetivo oferecer uma grande contribuição para melhorar os níveis de conforto e, ao mesmo tempo, aumentar a segurança, detectando situações de emergência, como, por exemplo, incêndios, fuga de gás e água, e evitando gastos energéticos desnecessários.

Neste trabalho, foi desenvolvido um controle e segurança infantil utilizando Arduino. A programação será feita via IDE (Ambiente de Desenvolvimento Integrado) e terá como função comunicar o Arduino com o sistema de controle. Devido à grande quantidade de acidentes infantis na cozinha residencial, um sistema de segurança deve ser implantado para evitar que crianças acionem dispositivos sem que os pais permitam o acesso das mesmas neste cômodo ou imediações da casa, evitando transtornos maiores. Conceitos de Árvore de Falhas (FTA), Ciclo de vida do produto e Failure Mode and Effects Analysis (FMEA) serão utilizados para a avaliação do sistema domótico. 


\section{PROBLEMA}

\subsection{Acidentes domésticos com crianças}

Segundo o Ministério da Saúde (2013) e a Organização Mundial de Saúde, os acidentes que mais acometem crianças de zero a nove anos são: afogamento, obstrução de vias aéreas (sufocação, estrangulamento e engasgamento), envenenamento e intoxicação, queimaduras e choques elétricos, acidentes com armas de fogo e outros. Deixar a criança ter acesso à cozinha sem uma prévia fiscalização pode gerar transtornos irreversíveis.

Conclui-se que, com esses problemas, pode-se criar ferramentas que facilitem o nosso dia a dia, dando segurança e comodidade por meio da utilização de tecnologia com fácil acesso e custo baixo, controlando a luminosidade, o funcionamento de motores e desligamento de gás utilizando automação. Alguns dados referentes à mortalidade infantil são ilustrados na Tabela 1:

Tabela 1 - Mortalidade por acidente na faixa etária de 0 a 9 anos.

\begin{tabular}{|c|c|}
\hline De 0 a 9 anos & 2012 \\
\hline Trânsito & 1038 \\
\hline Afogamento & 728 \\
\hline Sufocação & 718 \\
\hline Queimaduras & 220 \\
\hline Outros & 194 \\
\hline Queda & 171 \\
\hline Envenenamento & 68 \\
\hline Armas de fogo & 5 \\
\hline Total & 3142 \\
\hline
\end{tabular}

Fonte: Ministério da Saúde, 2013.

Comparados com dados de 2003 (Tabela 2), esses índices sofreram redução, mas ainda apresentam um número significativo de mortes nessa faixa etária. 
Tabela 2 - Mortalidade por acidentes de zero a nove anos, comparativo de 2003 e 2012.

\begin{tabular}{|c|c|c|c|}
\cline { 2 - 4 } \multicolumn{1}{c|}{} & 2003 & 2012 & Redução \\
\hline Envenenamento & 105 & 68 & $39 \%$ \\
\hline Queimadura & 350 & 220 & $37 \%$ \\
\hline Transito & 1456 & 1038 & $29 \%$ \\
\hline Outros & 272 & 199 & $28 \%$ \\
\hline Afogamento & 982 & 728 & $26 \%$ \\
\hline Quedas & 214 & 171 & $20 \%$ \\
\hline Sufocação & 736 & 718 & $3 \%$ \\
\hline Total & 4141 & 3142 & $24 \%$ \\
\hline
\end{tabular}

Fonte: Ministério da Saúde, 2013.

Uma solução visualizada para redução de acidentes domésticos seria o uso de automação. Caso ocorra o monitoramento, os pais podem saber se os filhos se encaminharam para a cozinha e, imediatamente, os mesmos são recolhidos do local não apropriado com segurança. Técnicas de análise com FTA e FMEA são utilizadas para identificar possíveis problemas de funcionamento do sistema projetado com o objetivo de melhorar a qualidade visando à necessidade do consumidor.

\section{METODOLOGIA}

A pesquisa para a realização do trabalho baseia-se em conceitos de automação residencial associados ao controle de sistemas pelo microcontrolador Arduino (McROBERTS, 2011). Objetivou-se projetar um sistema de segurança automatizado para prevenção e alerta contra acidentes domésticos na cozinha.

Dados sobre acidentes infantis foram levantados utilizando uma base oficial de informações (Ministério da Saúde, 2013), que define a viabilidade de implementação de um sistema frente a possíveis gastos extras que serão proporcionados em função ao desenvolvimento e finalização do protótipo e, consequentemente, do sistema propriamente dito. Os referidos dados serão analisados e dispositivos como FTA e FMEA serão utilizados para validar o sistema e mostrar a eficiência. 
Objetiva-se projetar um sistema Domótico que realizará o controle de luminosidade interna e externa de uma residência e um portão com acionamento automático. Visando a comodidade projeta-se também a inserção de um aplicativo associado a um smartphone, que será responsável pelos comandos de liga/desliga dos dispositivos. Um módulo bluetooth, que é um dispositivo acessório ao Arduino, é acoplado ao sistema para realizar a comunicação do Arduino com o smartphone. Associado a este tema, também utilizando Arduino, objetiva-se projetar um sistema de segurança automatizado para prevenção e alerta contra acidentes domésticos na cozinha.

\section{DESENVOLVIMENTO DO PROTÓTIPO}

\subsection{Objetivo geral}

Desenvolver um sistema em domótica para alertar os pais quando a criança estiver na cozinha.

\subsection{Objetivos específicos}

- Projetar um circuito utilizando Arduino e sensores que tenham como funcionalidade acionar uma buzina e mostrar em um display a presença de uma criança no ambiente. Quando a criança não estiver na cozinha, o sistema sinalizará que está tudo de acordo com a conformidade.

- Realizar a comunicação do Arduino com os dispositivos a serem controlados e escrever um software em linguagem C com a utilização do Ambiente de Desenvolvimento Integrado do Arduino para uso das interfaces de comunicação sem fio.

- Comprovar a funcionalidade do sistema e as vantagens que serão geradas em função de uma casa automatizada.

- Minimizar as dificuldades relacionadas à utilização de um sistema que pode ser visto como barreira para as pessoas que não têm familiaridade com a tecnologia.

Por meio de pesquisas e testes práticos, foi identificada uma solução para a prevenção de acidentes na cozinha da residência. Posteriormente, define-se a 
montagem do sistema de prevenção e controle. Os exemplos abaixo mostram o sistema proposto e de que forma ele atuará na prevenção de acidentes infantis. A Figura 1 esboça como será a implementação do sistema com o posicionamento dos sensores e a disposição na cozinha da residência.

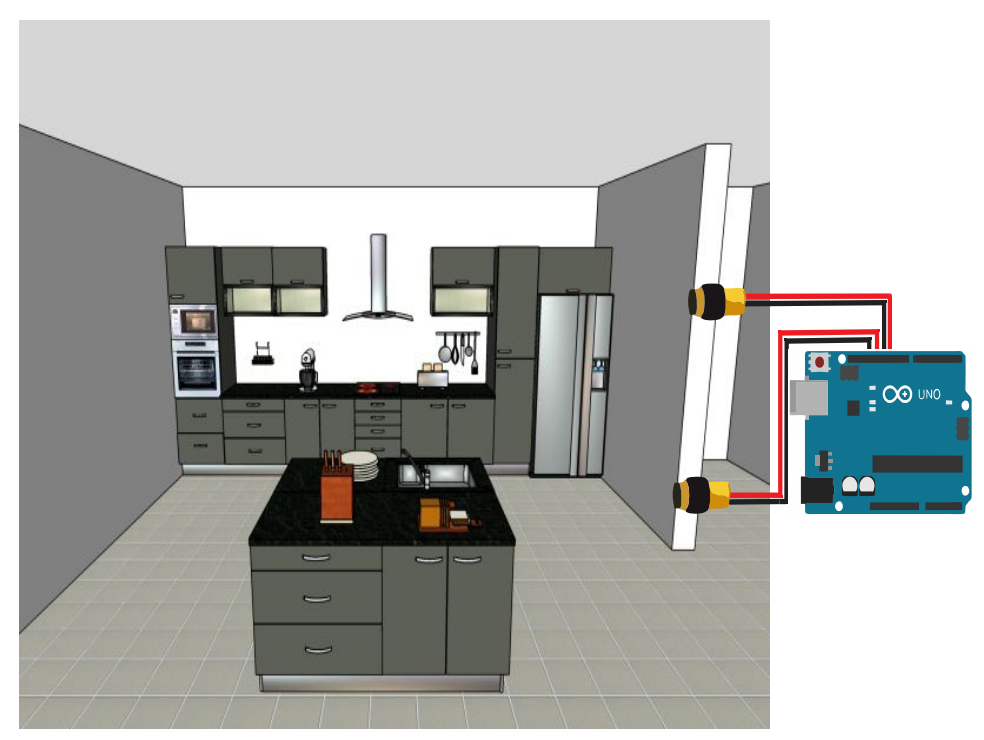

Figura 1 - Implementação do sistema de segurança na cozinha da residência. Fonte: Autor, 2016.

O sistema não será acionado na presença de uma pessoa que tenha medida de altura acima do especificado (Figura 2). Quem passa acima do segundo sensor infravermelho também terá acionado o sensor inferior, bloqueando o feixe de ambos ao mesmo tempo.

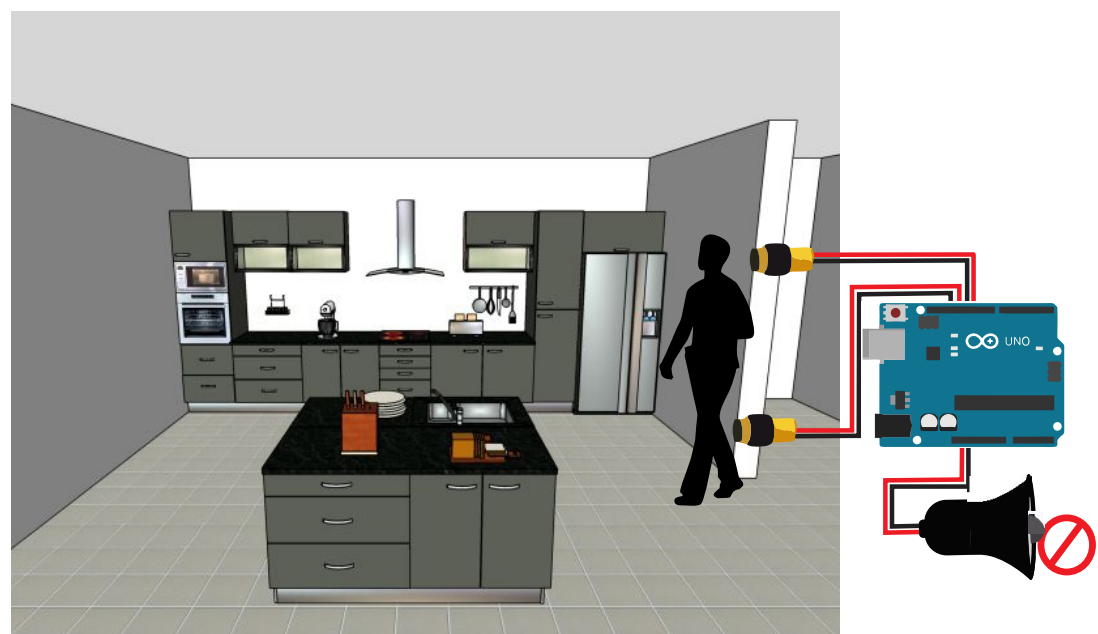

Figura 2 - Ação do sistema na presença de um adulto.

Fonte: Autor, 2016. 
No caso representado na Figura 3, quem tiver altura inferior ao sensor superior não acionará o mesmo, o acionamento será feito em função do bloqueio do feixe do sensor inferior.

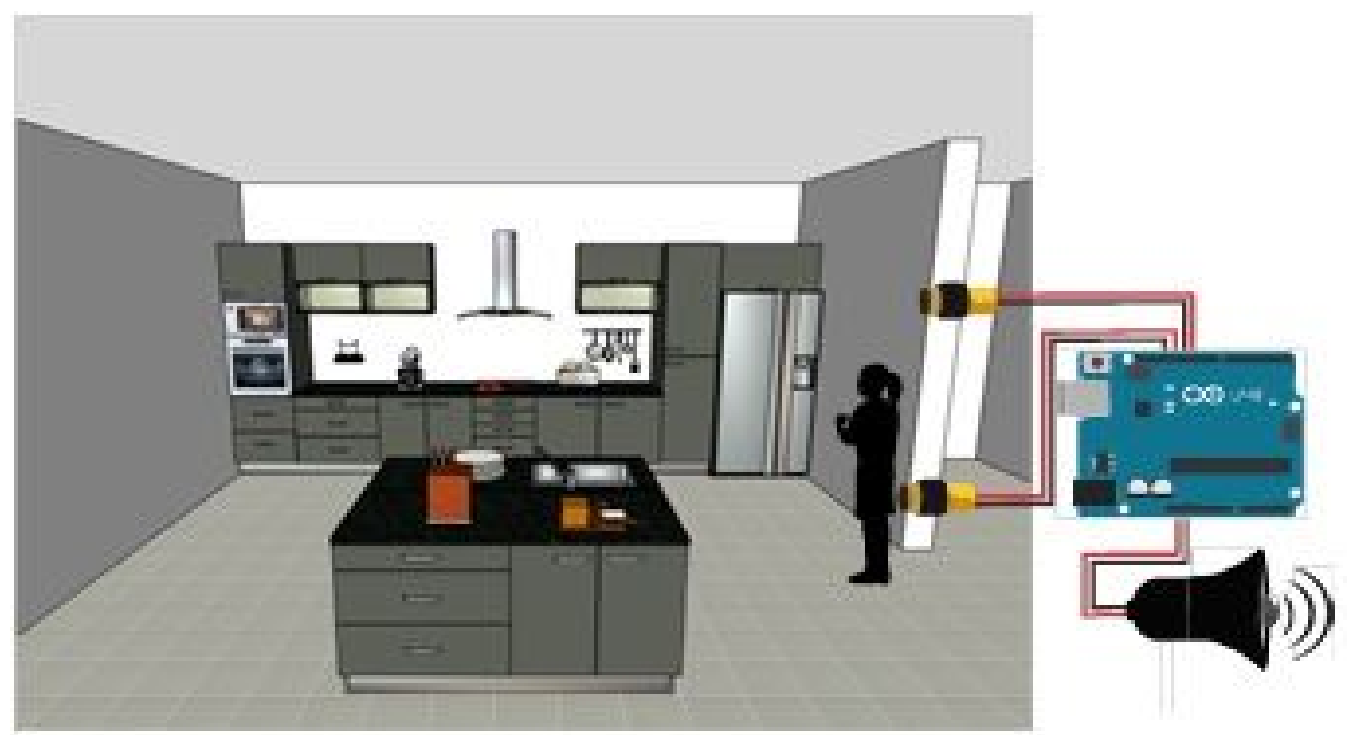

Figura 3 - Ação do sistema na presença de uma criança. Fonte: Autor, 2016.

A descrição do sistema segue especificada de acordo com a numeração da Figura 4:

(1) Dois sensores de proximidade infravermelho modelo E18-D80NK são posicionados na parede referente à porta da cozinha, um $0,2 \mathrm{~m}$ acima do solo e o outro a 1,50m acima do mesmo. Quando os dois sensores forem acionados (detecção de corpo ou objeto), o sistema não aciona o alarme, pois se trata da presença de uma pessoa maior que 1,50m. Quando apenas o sensor inferior detectar presença, um sistema de alarme é acionado, identificando que uma pessoa menor que 1,50m está em um ambiente perigoso (cozinha).

(2) Um Arduino Nano foi escolhido, pois tem a mesma eficiência de um Uno (outro modelo de Arduino); porém, devido ao seu tamanho reduzido, ocupa menor espaço e pode ser trabalhado em ambientes que não possuem superfície disponível para alocação de equipamentos. O Arduino é utilizado como dispositivo de controle do sistema, acionando o alarme quando a condição pré-definida na programação é satisfeita. 
(3) O display LCD tem como função mostrar quando a situação está ok (sem criança na cozinha) e quando a criança está em situação de perigo. A sugestão é que ele seja colocado em uma posição onde os adultos tenham facilidade para visualização.

(4) O Buzzer (dispositivo de alarme) é utilizado para avisar os adultos de presença de alguém menor que 1,50 na cozinha.

(5) O potenciômetro tem como funcionalidade variar a luminosidade do display LCD.

(6) Os dois leds servem para sinalizar a presença de criança na cozinha.

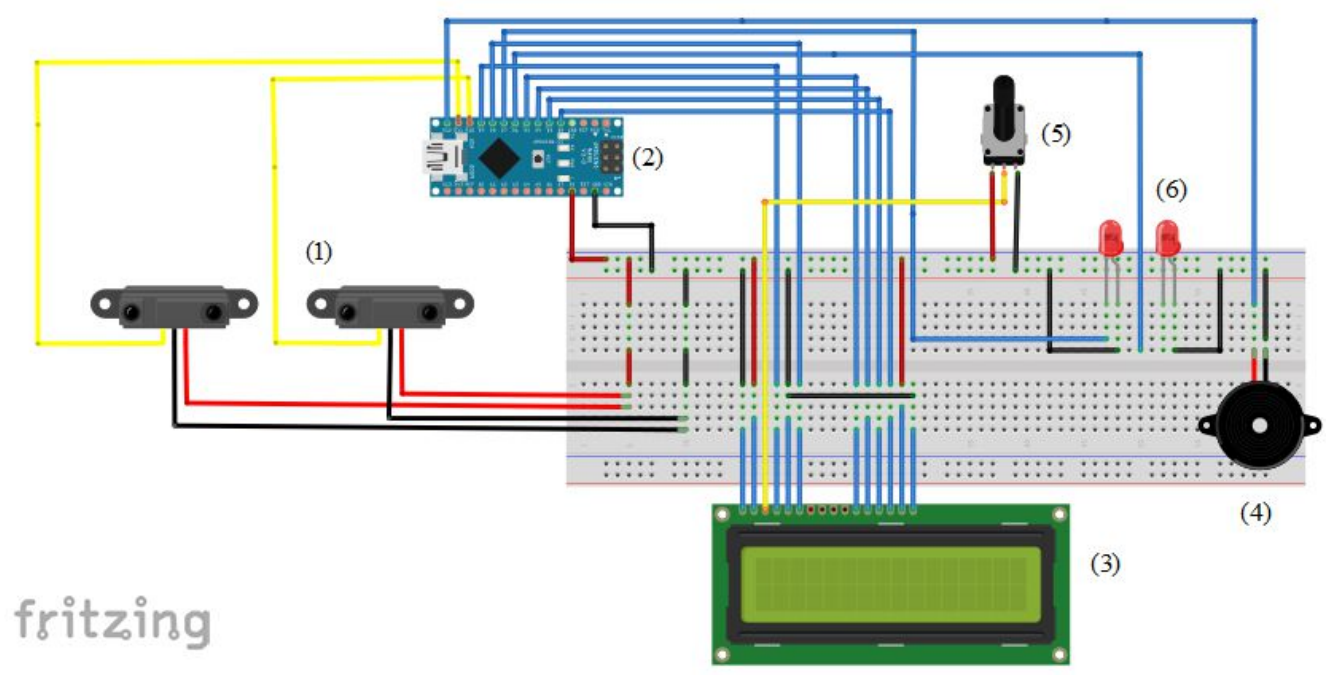

Figura 4 - Sistema de controle para a prevenção de acidente.

Fonte: Autor, 2016.

\subsection{Orçamento do Sistema}

O sistema proposto objetiva a redução de acidentes domésticos. Também apresenta um baixo custo de aquisição, visto que os equipamentos para confecção do projeto apresentam um preço acessível. A Tabela 3 apresenta um orçamento para confecção do protótipo: 
Tabela 3 - Orçamento do protótipo do projeto.

\begin{tabular}{|c|c|c|c|}
\hline Produto & Quantidade & $\begin{array}{c}\text { Preço por } \\
\text { Unidade (R\$) }\end{array}$ & $\begin{array}{c}\text { Total por } \\
\text { produto (R\$) }\end{array}$ \\
\hline Arduino Nano & 1 & 24,99 & 24,99 \\
\hline Sensor Infravermelho E18-D80NK & 2 & 24,99 & 49,98 \\
\hline Display LCD 16 x & 1 & 11,99 & 11,99 \\
\hline Buzzer 12mm 5V com oscilador interno & 1 & 3,98 & 3,98 \\
\hline Protoboard 830 furos & 1 & 18,99 & 18,99 \\
\hline Potenciômetro linear 10k & 1 & 1,30 & 1,30 \\
\hline $\begin{array}{c}\text { Jumpers macho-fêmea Premium } \\
\text { (1 pacote com 60 unidades) }\end{array}$ & 1 & 19,90 & 19,90 \\
\hline $\begin{array}{c}\text { Jumpers macho-macho Premium } \\
\text { (1 pacote com 60 unidades) }\end{array}$ & 1 & 19,90 & 19,90 \\
\hline Led Vermelho Alto Brilho & 2 & 0,15 & 0,30 \\
\hline Total & 11 & 126,19 & 151,33 \\
\hline
\end{tabular}

Fonte: Autor, 2016.

Caso o usuário final queira realizar todas as etapas de montagem, os itens apresentados na Tabela 4 seriam acrescentados. Em média, mesmo com a inserção de um profissional especializado, o custo de implementação do sistema é baixo frente à eficiência na prevenção de possíveis acidentes com crianças na cozinha.

Tabela 4 - Itens necessários para confecção do sistema completo sem a mão de obra de um profissional especializado.

\begin{tabular}{|c|c|c|c|}
\hline Produto & Quantidade & $\begin{array}{c}\text { Preço por } \\
\text { Unidade (R\$) }\end{array}$ & $\begin{array}{c}\text { Total por } \\
\text { produto (R\$) }\end{array}$ \\
\hline Placa Fenolite PCB ilhada 5x7 & 1 & 2,99 & 2,99 \\
\hline Ferro de Solda 60W & 1 & 23,99 & 23,99 \\
\hline Total & $\mathbf{2}$ & $\mathbf{2 6 , 9 8}$ & $\mathbf{2 6 , 9 8}$ \\
\hline
\end{tabular}

Fonte: Autor, 2016. 


\section{4 Árvore de Falhas}

A Análise por Árvore de Falhas (FTA) é utilizada para analisar as causas de riscos. A árvore de falhas é um modelo gráfico de combinações paralelas e sequenciais de falhas que podem resultar na ocorrência do efeito (cabeça da árvore). As falhas podem ser eventos associados com falhas de componentes, erro humano, falhas do sistema, assim como erros nos requisitos, erros de design e bugs em programas. E FTA utiliza lógica booleana (lógicas E e OU) para representar as combinações de falhas individuais que podem conduzir ao efeito. FTA é um método de análise qualitativa, entretanto, se as probabilidades individuais são conhecidas para todos os eventos básicos, a probabilidade do caminho crítico pode ser quantificada (AMBERKAR et al., 2001 apud YAMANE; SOUZA, 2007).

Após a conclusão do mapeamento de todas as possíveis causas, os índices de probabilidade de ocorrência para cada causa são definidos e deve-se ter o cuidado identificar probabilidades até o mesmo nível em todos os ramos, a fim de não penalizar os ramos que são mais bem explorados. Esses índices de probabilidades são definidos através de reuniões com especialistas da área, pois a quantificação de ocorrência de cada causa de cada problema se torna inviável devido à ineficiência dos apontamentos pelos operadores responsáveis (YAMANE; SOUZA, 2007).

\subsection{Prevenção de Possíveis Falhas no Sistema}

De acordo com o critério da árvore de falhas, FTA (Fault tree analysis), o diagrama é utilizado para determinar como uma anomalia que acontece em um sistema poderá ser causada pelas falhas e combinações de falhas de seus subsistemas e componentes. Essa análise acontece de cima para baixo, o chamado top-down, e tem por objetivo encontrar as causas fundamentais ou básicas de uma anomalia (FERNANDES, 2005). Utilizando-se este critério, montou-se o diagrama referente às possíveis falhas que este sistema pode apresentar.

O sistema é feito com blocos de erros associados com portas lógicas (OR) que representam a condição de um problema ou outro ocorrer ao mesmo tempo ou individualmente. 


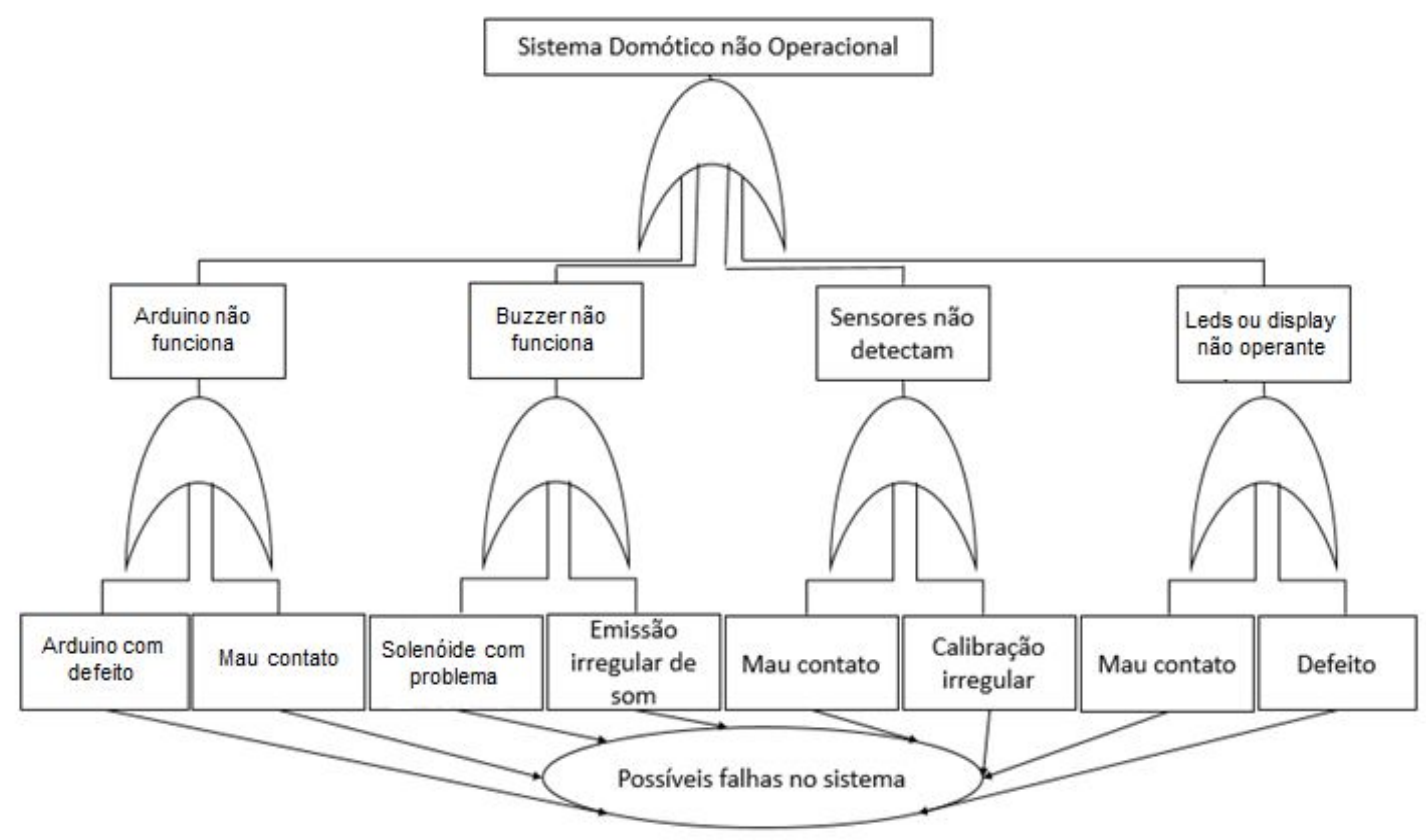

Figura 5 - Árvore de falhas referente ao Sistema Domótico.

Fonte: Autor, 2016.

Adaptando a técnica da árvore de falhas para o projeto, percebe-se que três parâmetros serão fundamentais na definição de possíveis falhas no sistema: 0 Arduino, o buzzer e os sensores infravermelho. O display LCD e os leds não param o sistema em caso de falha, apenas reduzem os recursos de alerta para o usuário. Se um desses três dispositivos parar, tem-se uma interrupção do sistema. O Arduino Nano tem como dispositivo mais importante seu processador, que é um Atmega328. Ele é o elemento central, dada a sua importância no funcionamento.

\subsection{Sistema em Funcionamento}

O funcionamento do sistema pode ser visualizado nas figuras. $\mathrm{Na}$ situação representada pela Figura 6, os sensores não têm interrupção do feixe ou têm interrupção simultânea. Os leds ficam desligados, o buzzer não emite som e no display aparece a mensagem "Situação ok", identificando que não há presença de crianças. 


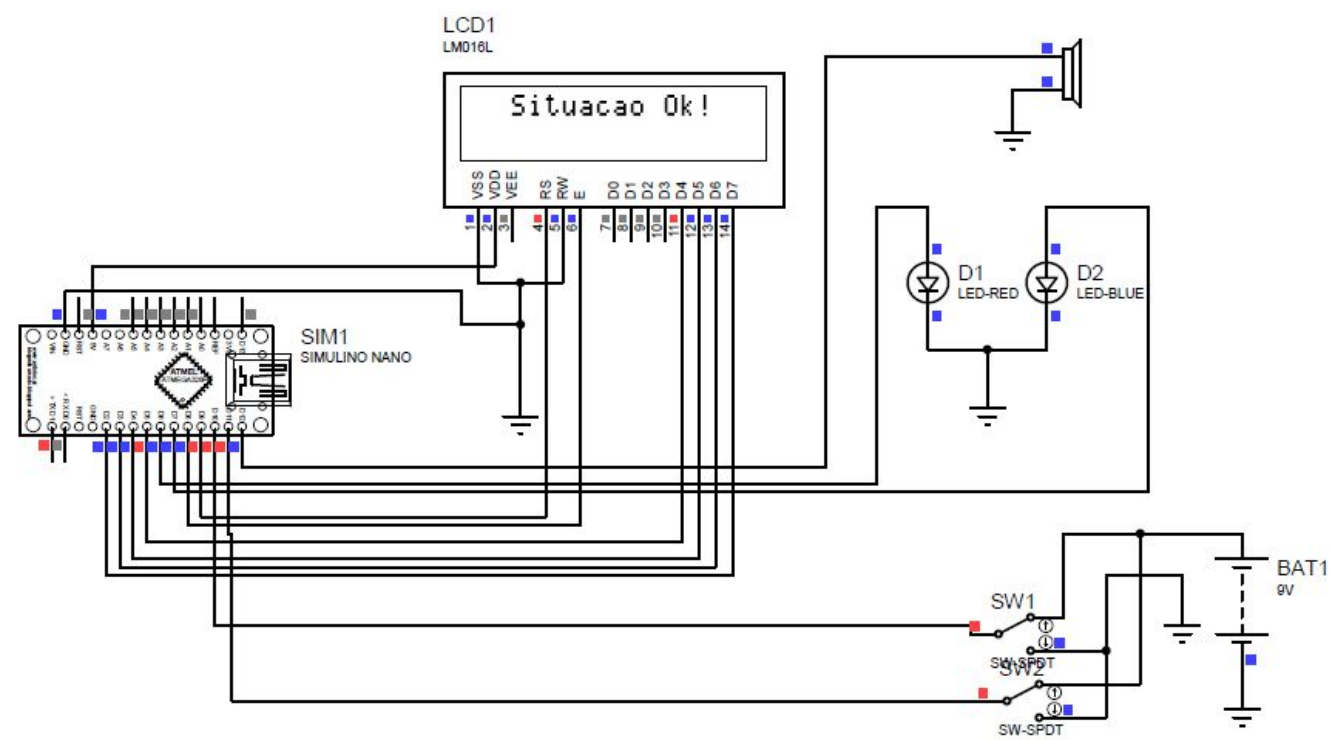

Figura 6 - Cozinha vazia ou sem a presença de criança.

Fonte: Autor, 2016.

A situação representada na Figura 7 identifica a presença de criança na cozinha. O buzzer começa a emitir som de alerta, os leds acendem e o display mostra a mensagem "Criança na Cozinha". Esse alerta é enviado para que os pais ou responsáveis tomem as providências para evitar que a criança se machuque.

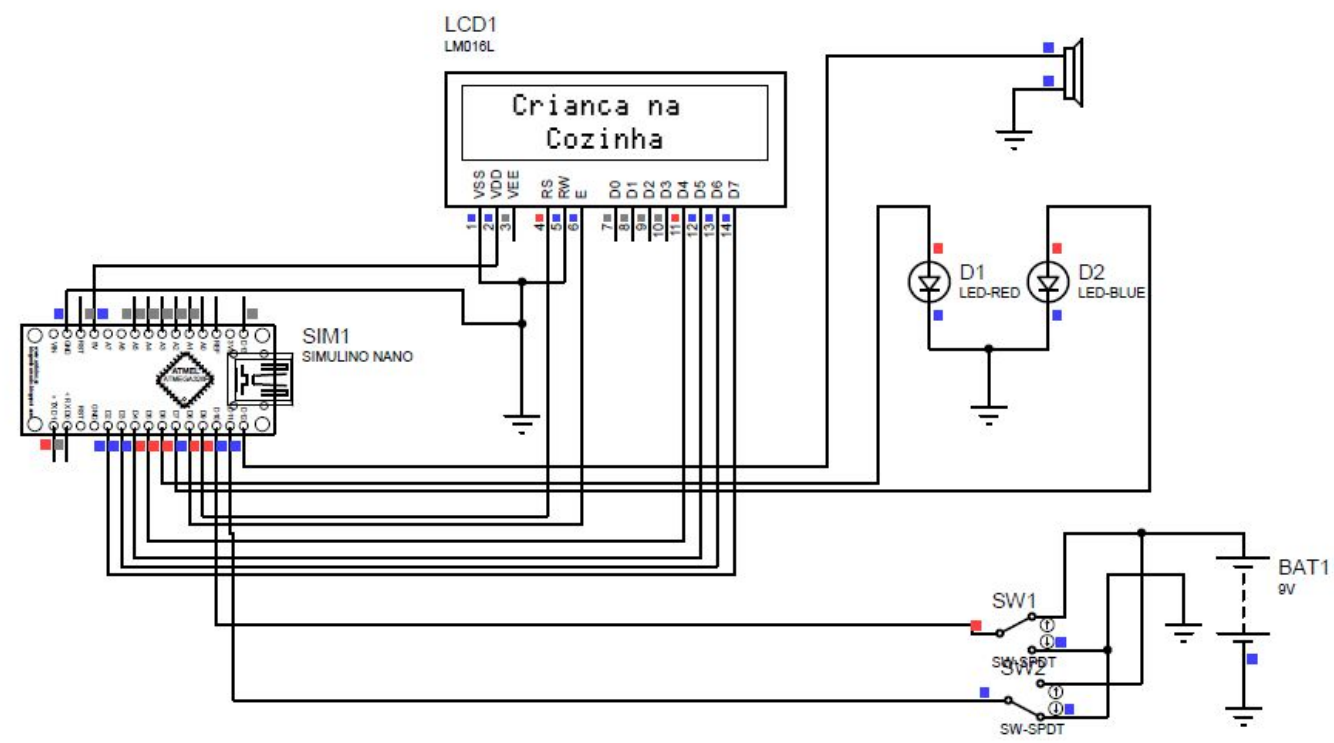

Figura 7 - Cozinha com a presença de criança.

Fonte: Autor, 2016. 
O protótipo gerado após o processo de simulação computacional é apresentado na Figura 8. O sistema é montado inicialmente em protoboard, para garantir que tudo funcione de acordo com o esperado. Posteriormente, o objetivo é a geração de uma placa de circuito impresso $(\mathrm{PCl})$, objetivando a redução de ruídos e de outros problemas advindos de um protótipo.

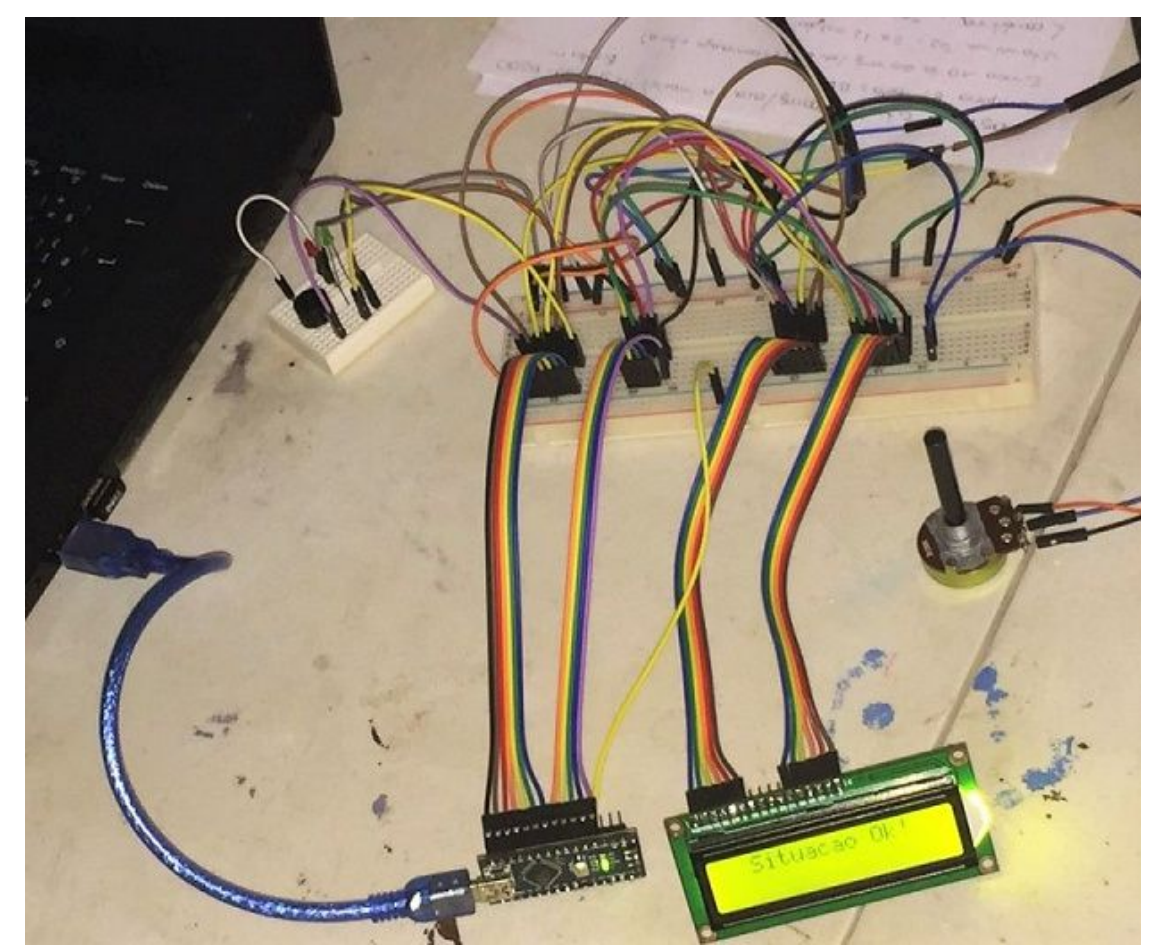

Figura 8 - Protótipo do Sistema de Segurança. Fonte: Autor, 2016.

\section{CONCLUSÃO}

Um sistema de segurança foi proposto com o intuito de alertar os responsáveis que crianças de 0 a 5 anos estão presentes na cozinha sem qualquer adulto por perto. Dois sensores colocados na cozinha acionam um buzzer, que tem como função alertar os pais avisando que uma criança está presente no ambiente que oferece risco de acidentes. Um display LCD posicionado em um local estratégico alerta para a presença de criança na cozinha. O sistema se apresenta com boa eficácia, pois foi projetado com baixo custo e fácil otimização, sendo 
manuseado por pessoas que não têm habilidade com eletrônica e automação. O protótipo pode ser colocado no caixonete da porta e a utilização de um Arduino Nano teve como funcionalidade a possibilidade de implementação do sistema em locais com pouco espaço.

O protótipo mostra um sistema com baixo custo de aquisição e manutenção e, com a análise pelo método de árvore de falhas, percebe-se que o sistema tem baixo risco de apresentar problemas, devido à durabilidade dos materiais utilizados e fácil acesso dos mesmos. Com pesquisas de mercado, pode-se perceber que a reposição de material apresenta um baixo custo, valendo o investimento no projeto. Como proposta futura, pode-se empregar tecnologia GSM, criando uma técnica para enviar mensagem para os pais, indicando que a criança está na cozinha.

\section{REFERÊNCIAS}

ARAÚJO, I. B. Q. et al. Desenvolvimento de um protótipo de automação predial/residencial utilizando a plataforma de prototipagem eletrônica Arduino. In: Anais XL CONGRESSO BRASILEIRO DE EDUCAÇÃO EM ENGENHARIA (Cobenge), Belém, UFPA. 2012.

BRASIL. MINISTÉRIO DA SAÚDE (MS). CONSELHO NACIONAL DE SAÚDE; Resolução n 466, de 12 de dezembro de 2012. Diário Oficial da União, 2013.

DE ANDRADE, Thamara Queiroz et al. Desenvolvimento de um sistema baseado na domótica, 2016. In: XXXV ENCONTRO NACIONAL DE ENGENHARIA DE PRODUÇÃO, PERSPECTIVAS GLOBAIS PARA A ENGENHARIA DE PRODUÇÃO, Fortaleza, 2015. p. 1-21.

FERNANDES, JOSÉ MÁRCIO RAMOS. Proposição de abordagem integrada de métodos da qualidade baseada no FMEA. Dissertação. Pontifícia Universidade Católica do Paraná. Curitiba, 2005.

FERRONI, Eduardo et al. A plataforma Arduíno e suas aplicações. Revista da UIIPS, v. 3, n. 2, 2015. Disponível em: <http://www.brasil.gov.br/saude/2013/09/acidentes-domesticosainda-sao-principal-causa-de-morte-de-criancas-ate-9-anos>. Acesso em: 22/03/2017.

McROBERTS, Michael. Arduino Básico. São Paulo: Novatec Editora, 2011.

Ministério da Saúde. Centro Nacional de Desenvolvimento Sanitário (CNDS) PICTÓRICO; ACIDENTES DOMÉSTICOS INFANTIS - Evitemos as Situações de Risco; 2013.

MONTEIRO, Pedro Jose Santos. Aplicação Android para sistema de Domótica. Dissertação. Curso de Tecnologia e Gestão, Instituto Politécnico de Viseu, Viseu, 2015.

MONK, Simon. Programação com Arduino: Começando com Sketches. Série Tekne. AMGH Editora, 2013. 
SILVA, Mauricio César; GAMBARATO, Vivian Toledo Santos. Domótica e tecnologias utilizadas na automação residencial. Tekhne e Logos, v. 7, n. 2, p. 56-67, 2016.

SILVEIRA, Sidnei Renato; RIBEIRO, Vinicius Gadis; MACHADO MARTINS, Márcio. Uma solução de baixo custo para implementação de domótica. Revista de Sistemas e Computação-RSC, v. 4, n. 2, 2015.

STOPPA, Marcelo H. et al. 2013. Domótica: uma solução para a vida moderna-automação residencial com controle via Web. Revista CEPPG - CESUC - Centro de Ensino Superior de Catalão, Ano XVI n $28,1^{\circ}$ Semestre/2013

YAMANE, Alexandre Kenji; SOUZA, LGM. Aplicação do mapeamento de árvore de falha (FTA) para melhoria contínua em uma empresa do setor automobilístico. In: XVII ENCONTRO NACIONAL DE ENGENHARIA DE PRODUÇÃO, ENEGEP, 2007. 